Revista Eletrônica de Ciência Administrativa (RECADM) - ISSN 1677-7387

Faculdade Cenecista de Campo Largo - Coordenação do Curso de Administração v. 4, n. 1, maio/2005 - http://revistas.facecla.com.br/index.php/recadm/

\title{
AS NOVAS COMPETÊNCIAS PARA O ENGENHEIRO DE SISTEMAS NA TOMADA DE DECISÃO
}

\author{
Maia, Edwillian \\ Universidade Estácio de Sá e Univercidade, Mestre em Administração \\ Edwillian@bol.com.br \\ Vilas Boas, Ana Alice \\ Universidade Federal Rural do Rio de Janeiro, PhD. em Administração \\ analice@ufrri.br
}

\section{RESUMO}

No novo contexto econômico mundial, onde o conhecimento passa a ser considerado o fator de produção fundamental para as organizações e um diferencial competitivo sustentável a médio e longo prazo, a aprendizagem e a gestão do conhecimento tácito e de mercado vêm despertando a atenção de estudiosos no mundo inteiro. Nos últimos anos, vários estudos têm sido desenvolvidos sobre este tema, mas poucos enfocam especificamente os profissionais que atuam nos sistemas de informação e sua participação no planejamento dos rumos das organizações. O objetivo deste trabalho, exploratório, é oferecer subsídios para estratégias educacionais para o engenheiro de sistemas de informação a partir da investigação direta da dimensão "conhecimento" em pequenas e medias empresas, e mostrar que a tomada de decisão em uma empresa necessita do conhecimento de um engenheiro de sistemas sintonizado com as tendências de mercado para que haja maior capacidade de geração de empregos e fortalecimento da economia, em um mundo em mutação acelerada. A ampliação das atribuições reúne competências técnicas de modelagem, habilidades de liderança, inter-relacionamento e motivação, que, entre outras, tornaram o engenheiro da informação um gestor nas pequenas e médias empresas.

Palavras-chave: Decisão, Empreendedorismo, Sistema de Informação. 
Revista Eletrônica de Ciência Administrativa (RECADM) - ISSN 1677-7387

Faculdade Cenecista de Campo Largo - Coordenação do Curso de Administração v. 4, n. 1, maio/2005 - http://revistas.facecla.com.br/index.php/recadm/

In the current world by economy context, in which knowledge is coming to be considered the fundamental production factor for organizations and a sustainable competitive differential within mid and long terms, researchers in general, are starting to pay attention to the learning and managing process of tacit and trade knowledge. In the most recent years, several researches have been developed this subject. However, only a few studies focused specifically on the professionals who work with information systems. They also focus on their participation in the planning of the companies' future. The maim of this exploratory study is to offer subsidies to educational strategies for the engineer of information systems, taking the straight investigation of the "knowledge" dimension into small and middle-sized companies as the starting point, and to show that the decision making in a company must take the knowledge of the engineer of systems into account, mainly for being this professional aware of the trading tendencies capable of raising the number of employment and strengthening the economy, in a world of accelerated mutation. The broadening of the attributes combines technical know-how of modeling, leadership abilities, inter-relationship and motivation which, among others, most of all, have helped the engineer of information becoming a manager of small and middle-sized companies.

\section{INTRODUÇÃO}

Sistemas de Informação compostos por redes de comunicação, computadores e programas são, hoje, a infra-estrutura sobre a qual grande parte das corporações na economia mundial se apóia. Muitos empreendimentos no mercado global dessa economia estão estruturados fortemente sobre eles. Algumas empresas projetaram seus negócios apenas sobre essa infraestrutura, como as empresas que existem apenas na Internet e enquanto outras, de pequeno porte, alavancaram seus negócios devido aos recursos oferecidos por essas novas tecnologias. A computação distribuída, pedra fundamental dos Sistemas de Informação atuais, pode ser considerada a resposta natural da tecnologia, para as mudanças estruturais que ocorrem nas organizações, delegando poder e responsabilidade dos altos escalões aos níveis intermediários 
Revista Eletrônica de Ciência Administrativa (RECADM) - ISSN 1677-7387

Faculdade Cenecista de Campo Largo - Coordenação do Curso de Administração v. 4, n. 1, maio/2005 - http://revistas.facecla.com.br/index.php/recadm/

e operacionais. Essas mudanças permitem maior flexibilidade e agilidade às organizações, mas demandam a otimização dos recursos humanos e computacionais.

Com o advento da computação distribuída, o paradigma mudou e o poder passou a ser distribuído, ocasionando uma diminuição de controle. Nesse contexto, a baixa produtividade, a indisponibilidade dos Sistemas de Informação e outros fenômenos relacionados à distribuição do ambiente, passaram a causar um impacto direto nos negócios das empresas. Uma vez que o profissional dos Sistemas de Informação estavam presentes em todas as etapas do processo de reorganização de dados para a adequação às novas tecnologias emergentes, a sua capacidade de apurar e resolver problemas teve que ser apurada e adequada à nova realidade de mercado.

Foi necessária a criação de uma disciplina de gerenciamento que conseguisse manter os usuários dos sistemas com a liberdade conquistada, ao mesmo tempo que se controlava o ambiente, tornando-o mais homogêneo, com melhor desempenho e bem mais administrado.

A abordagem aqui apresentada não se compõe de conceitos tão definitivos que, uma vez compreendidos, permitam ser empregados sem a adequada análise criteriosa, mas apresenta idéias bastante práticas que podem levar os que as utilizam, a atingir seu objetivo de satisfazer os empreendedores na obtenção de uma decisão criteriosa sobre os rumos que a empresa deva tomar quanto a aplicação prática das novas tecnologias no segmento de mercado a qual está relacionada.

\subsection{Problema de Pesquisa}

Este trabalho se propõe a contribuir para o exame dos desafios enfrentados por empresas no presente, apresentando uma abordagem que permita às corporações e organizações menores, como as pequenas empresas, perceberem a importância do Engenheiro de Sistemas na tomada de decisão, uma vez que esse profissional participa de todo o processo de coleta e tratamento 
Revista Eletrônica de Ciência Administrativa (RECADM) - ISSN 1677-7387

Faculdade Cenecista de Campo Largo - Coordenação do Curso de Administração v. 4, n. 1, maio/2005 - http://revistas.facecla.com.br/index.php/recadm/

de dados, desde a sua origem até a utilização da informação no processo de tomada de decisão.

Para que se tenha o perfil desse profissional no mercado moderno, é fundamental o emprego de técnicas que apontem o caminho para se chegar a esses objetivos, métodos de como tomar as decisões alinhadas com os objetivos da organização e formas de avaliar permanentemente os resultados. Encontra-se no Anexo desta pesquisa uma grade curricular do curso de Engenharia de Sistemas, aplicada por uma universidade de Goiânia. Por não ser de propósito geral, as premissas que limitam o emprego da abordagem proposta são apresentadas ao longo do trabalho. Abordagens científicas são as ferramentas empregadas desde o Renascimento para, através de procedimentos sistemáticos e baseados na razão, chegar-se a conclusões gerais que possam ser utilizadas para os mais diversos fins. Uma vez de posse de um método científico, uma pessoa adequadamente preparada é capaz de repetir experimentos e projetos, chegando aos mesmos resultados que os que o formularam.

Ambientes corporativos ou ambientes computacionais são os termos que descrevem genericamente os Sistemas de Informação, e são constituídos pelos programas aplicativos, pelos computadores, pelas redes de comunicação locais e geográficas e pelo conjunto de pessoas que utilizam e suportam esses recursos. A disciplina de Gerenciamento de Ambientes Computacionais Corporativos, ou simplesmente Gerenciamento de Ambientes, é bastante nova, se comparada à Metodologia Científica. Ainda nos anos 60, essa disciplina se restringia ao mundo dos computadores de grande porte, mainframes, nos quais o controle era rígido, a liberdade dos usuários restrita e o poder dos que controlavam os sistemas era absoluto.

O problema abordado pela pesquisa refere-se a:

- Inexistência de uma abordagem voltada a tomada de decisão

- Inexistência de uma estrutura acadêmica adequada

- Má utilização da informação enviada aos administradores 
Revista Eletrônica de Ciência Administrativa (RECADM) - ISSN 1677-7387

Faculdade Cenecista de Campo Largo - Coordenação do Curso de Administração v. 4, n. 1, maio/2005 - http://revistas.facecla.com.br/index.php/recadm/

\subsection{Objetivo}

O objetivo geral do trabalho é contribuir para delinear uma abordagem centrada nas novas competências do Engenheiro de Informação na tomada de decisão de forma que seja viável, cientificamente correta e fundamentada em princípios consagrados tecnicamente, tanto no âmbito acadêmico quanto comercial.

Como objetivos específicos tem-se:

- Verificar a forma de atuação do Engenheiro de Informação na tomada de decisão.

- Propor uma forma nova de atuação desse profissional para levar vantagem competitiva à empresa.

- Propor sugestões para adequação do currículo da área de Engenharia de Sistemas

\subsection{Suposições}

Esse trabalho parte do suposto de que é possível e necessário ter no conselho administrativo de uma empresa um profissional de tecnologia de base, com formação e vivência no mercado, para que as decisões então tomadas possam ser baseadas em uma realidade interna que explore tanto aspectos produtivos quanto logísticos.

Essa abordagem deve contemplar diversos aspectos relacionados:

Á situação presente da organização:

- Sistemas do contexto atual,

- Necessidades do negócio da empresa e;

- Informações que podem ser fornecidas pelos usuários dos Sistemas de Informação para alavancar a atividade da gerência.

Ao contexto desejável futuramente:

- Resultados desse gerenciamento sugerido;

- Processos que relacionam pessoas aos sistemas na tomada de decisão. 
Revista Eletrônica de Ciência Administrativa (RECADM) - ISSN 1677-7387

Faculdade Cenecista de Campo Largo - Coordenação do Curso de Administração v. 4, n. 1, maio/2005 - http://revistas.facecla.com.br/index.php/recadm/

- Informações que podem ser fornecidas pelo Engenheiro de Informação para permitir a implantação de novos processos.

\subsection{Abrangência - Limitação e Relevância do Estudo}

Delimita-se o escopo desse trabalho em diversas dimensões. Em primeiro lugar, nos padrões de protocolos de comunicações desenvolvidos até o presente e os princípios do Controle da Qualidade Total (Campos, 1992). A escolha dessa referência se deve à sua estabilidade e capacidade de direcionar grande parte dos produtos, padrões e modelos desenvolvidos posteriormente (Tina, 1998).

Em segundo lugar, o enfoque da abordagem está voltado ao ambiente corporativo de empresas que operam em mercados de pequeno e médio porte, onde a tomada de decisão possa ser partilhada pelos proprietários do negócio.

Em terceiro lugar, é levado em conta o contexto atual da tecnologia da informação, seja em produtos do mercado, seja em ambientes de pesquisa e desenvolvimento, seja na discussão dos fóruns técnicos pertinentes.

No entanto este estudo apresenta limitações quanto a bibliografia. A pesquisa para realização desse trabalho não encontrou referências bibliográficas públicas suficientes sobre abordagens similares à proposta ou abordagens para implementação de gerenciamento de Sistemas de Informação em pequenas e médias empresas com vistas ao compartilhamento da tomada de decisão. Apenas um dos trabalhos citados (Clementi, 1999), realmente está enquadrado no conceito de metodologia para implementação de gerenciamento e ao mesmo tempo faz parte do grupo de documentos de acesso público e irrestrito.

\section{REFERENCIAL TEÓRICO}

Este capítulo apresenta os fundamentos teóricos e a base para o estudo proposto. Ele inicia-se com a contextualização histórica que levou ao surgimento e desenvolvimento das tecnologias da informação. Em seguida aborda um levantamento das competências exigidas do Engenheiro de Informação e termina com algumas considerações sobre a estrutura curricular dos cursos de 
Revista Eletrônica de Ciência Administrativa (RECADM) - ISSN 1677-7387

Faculdade Cenecista de Campo Largo - Coordenação do Curso de Administração v. 4, n. 1, maio/2005 - http://revistas.facecla.com.br/index.php/recadm/

Engenharia a fim de fazer um link entre exigências do mercado e atual formação deste profissional.

\subsection{O Histórico da Globalização}

A globalização, ao longo dos últimos anos, tem convivido com sucessivas crises, demonstrado sempre surpreendente capacidade de superação. Essa atmosfera de constante renovação reflete-se no setor produtivo com a incorporação de novas tecnologias e com a alteração das formas de organização da produção e do trabalho. As empresas, igualmente e por reflexo, apresentam momentos de expansão seguidos de outros de retração de suas atividades de mercado, organizando novas estruturas submetidas a flexibilização e reestruturações constantes. Esse processo é complexo e de intenso desafio para as empresas que, por decisões nem sempre bem sucedidas, falem ou se arrastam em eternos prejuízos. Muitas vezes, uma decisão acertada demora a ser tomada provocando grandes transtornos ao negócio. Dentre essas decisões, constam as fusões ou aquisições de empresas como alternativas para saída das dificuldades desenhadas pelo cenário do capitalismo global. O fenômeno das crises cíclicas sugere que a instabilidade da economia é própria do capitalismo globalizado, impondo como condição própria para a sobrevivência das organizações a renovação constante.

\subsection{As Competências do Engenheiro de Informação.}

Num passado muito recente exigia-se do engenheiro basicamente habilidades técnicas e capacidade de desenvolver projetos específicos de cada área. Porém, com o mercado globalizado, a estas habilidades devem-se adicionar outras qualificações que, às vezes, não estão inseridas nos cursos de engenharia. Neste terceiro milênio, há a necessidade de acrescentar-se mais conhecimentos de aspectos administrativos, comunicação oral e escrita e relações humanas aos conhecimentos técnicos, matemáticos e físicos, para abrir o leque de informações de quem deseja seguir sua carreira com eficácia (Rompelman, 2001).

A tecnologia não alterou a natureza humana, mas lançou definitivamente uma nova forma para abordagem de temas como produtividade, eficiência, 
Revista Eletrônica de Ciência Administrativa (RECADM) - ISSN 1677-7387

Faculdade Cenecista de Campo Largo - Coordenação do Curso de Administração v. 4, n. 1, maio/2005 - http://revistas.facecla.com.br/index.php/recadm/

espírito de equipe e crescimento de empresas e funcionários, temas presentes num ambiente de trabalho cada vez mais competitivo e internacionalizado (Hoffman, 2001).

É sob esta ótica que os engenheiros precisam enxergar os desafios da nova era. Em Exame (2000), lemos que há pessoas preparadas para se adaptar ao novo cenário, ou seja, pessoas que absorvem rapidamente os novos conhecimentos e seguem jogando. Estas pessoas, ao corrigir a própria rota, vão passar provavelmente pela tempestade com a sua empregabilidade intacta. Mas, há pessoas que não têm a mesma capacidade de adaptação. Algumas não perceberam a nova direção do vento. Outras não estão dispostas ou não estão conseguindo se reciclar.

Essa dura realidade é mais desafiadora para o engenheiro recém-formado, porque apesar de possuir pouca experiência profissional, o seu título lhe confere prerrogativas supostamente dominadas, que muitas vezes precisam ser melhor desenvolvidas. Espera-se que o futuro engenheiro seja capaz de confrontar-se com problemas típicos, bem como com problemas originais de engenharia, empregando de forma eficiente os fundamentos científicos, conhecimentos tecnológicos e os métodos da sua profissão. Ele deve, portanto, mostrar competência na formulação de tais problemas, na escolha dos métodos para a sua solução, na crítica dos resultados e na sua comunicação oral e escrita (Nascimento, 1993).

Até os anos 50, admitia-se que o ensino obtivera êxito se o diplomado houvesse adquirido o conhecimento e as habilidades suficientes para dar início a uma carreira. Em suma, o engenheiro típico dos anos 50 era bem preparado em ciências. Ele aplicava esse conhecimento na solução de problemas complexos, de alta tecnologia, do tipo daqueles que são encontrados no planejamento de sistemas complexos, em áreas como a militar, a industrial e a aeroespacial.

Ele fazia isso como integrante de uma equipe de uma organização oficial de grande porte, bem equipada e bem estruturada: ele trabalhava numa agência cujas atividades estavam de acordo com seu foco de interesse e sua especialidade técnica. Entretanto, o engenheiro "moderno" era menos especializado, mas tinha várias outras habilidades, ou seja, o tipo de engenheiro 
Revista Eletrônica de Ciência Administrativa (RECADM) - ISSN 1677-7387

Faculdade Cenecista de Campo Largo - Coordenação do Curso de Administração v. 4, n. 1, maio/2005 - http://revistas.facecla.com.br/index.php/recadm/

ideal dos anos 90 era de uma espécie diferente. Os formandos daquela década eram igualmente bem preparados quanto aos fundamentos, mas num conjunto mais diversificado de disciplinas.

Segundo Rompelman (2001), os Engenheiros de Informação estavam preparados para o trabalho em equipe, capazes de articular, comunicar e defender suas propostas e aberto à negociação, além disso sabiam como lidar com a incerteza.

O engenheiro do terceiro milênio precisa estar bem mais preparado para enfrentar os desafios (Carvalho, 1988), caso contrário seu novo emprego estará cada vez mais longe de ser conquistado, pois seus conhecimentos específicos dificilmente se enquadrarão nas exigências do mercado. Caso ele esteja trabalhando, precisa optar pela educação continuada. Se não optar por esta situação poderá perder seu emprego num futuro bem próximo.

Segundo Oliverra (2000), a relação trabalho-emprego-salário está se modificando muito rapidamente e a troca do emprego pelo salário por participação está modificando todo o mercado de trabalho. As centrais sindicais já estão mudando o foco de sua luta quando não brigam mais pela manutenção do emprego mais sim do salário. Esta abordagem nos faz ver o quanto o trabalho do Engenheiro de Sistemas pode ser aproveitado de forma a adequar a empresa a esta nova fase evolutiva do mercado de trabalho, ressaltando as qualidades de liderança inerente a profissão tanto do engenheiro quanto do empresário.

Em Mattar (2000), estão apresentadas variáveis para caracterizar um líder e essas variáveis são fundamentais para a sobrevivência profissional. Apesar de não especificarem o tipo de profissional que nelas se enquadram, muitas podem ser estendidas aos engenheiros, conforme seqüência a seguir.

- Ambicioso: tem sempre desejo por mais; almeja riqueza, poder e glória;

- Analítico: examina detalhadamente a situação antes de decidir;

- Autocrítico: sabe avaliar e julgar suas atitudes positiva ou negativamente a fim de melhorar sempre;

- Autoritário: quer ter o direito ou poder de se fazer obedecer e de tomar decisões;

- Sensato: toma atitudes razoáveis: julga com ponderação, equilíbrio e racionalidade; 
Revista Eletrônica de Ciência Administrativa (RECADM) - ISSN 1677-7387

Faculdade Cenecista de Campo Largo - Coordenação do Curso de Administração v. 4, n. 1, maio/2005 - http://revistas.facecla.com.br/index.php/recadm/

- Receptivo a aprendizagem: facilidade de adquirir conhecimentos através de experiências próprias e de terceiros;

- Carismático: tem o dom natural de atrair e mobilizar as pessoas;

- Comunicativo: tem a capacidade em transmitir informações;

- Conciliador: consegue harmonizar situações e idéias conflitantes;

- Confia: acredita na capacidade e integridade das pessoas;

- Confiável: tem credibilidade e inspira confiança;

- Conhecedor: possui amplo conjunto de conhecimentos tanto do negócio como em cultura geral; diz-se daquele que se interessa por diversas áreas do conhecimento;

- Consistente: possui coerência em suas ações e idéias;

- Corajoso: assume riscos e aceita desafios;

- Crítico: sabe analisar e identificar erros e acertos;

- Desafiador: estimula a equipe a superar limites,

- Determinado: esforça-se para alcançar objetivo; é decidido; obstinado e resoluto;

- Dinâmico: é ágil e ativo;

- Empreendedor: é capaz de idealizar, iniciar, implantar, realizar idéias, projetos, empreendimentos (Rompelman, 2001);

- Equilibrado: possui prudência; moderação; estabilidade mental e emocional;

- Estratégico: preocupa-se com o horizonte, com o futuro e a direção a seguir;

- Ético: age de acordo com os valores moralmente aceitos pela sociedade;

- Experiente: possui um grande conhecimento do seu trabalho ou de sua área de atuação;

- Direcionado às pessoas: dá importância à motivação, ao desenvolvimento e ao relacionamento da sua equipe;

- Inovador: introduz novas idéias, atitudes, valores, experiências, processos e procedimentos;

- Justo: age com equidade e imparcialidade;

- Lógico: age de forma racional e não por impulso ou emocionalmente;

- Mente aberta: está disposto a ouvir e aceitar novas idéias, sugestões, propostas, críticas, etc.;

- Motivador: consegue despertar o interesse e o entusiasmo; 
Revista Eletrônica de Ciência Administrativa (RECADM) - ISSN 1677-7387

Faculdade Cenecista de Campo Largo - Coordenação do Curso de Administração v. 4, n. 1, maio/2005 - http://revistas.facecla.com.br/index.php/recadm/

- Multifuncional: é capaz de realizar/ exercer várias tarefas/funções;

- Negociador: sabe ponderar e conduzir a negociação de forma que as partes saiam satisfeitas;

- Objetivo: relaciona-se e age de forma clara e direta;

- Orientador: norteia, ensina e aconselha sua equipe em todos os aspectos;

- Persuasivo: induz e convence as pessoas;

- Planejador: define metas, objetivos, organiza recursos e define ações antes de agir;

- Proativo: tem iniciativa e toma decisões antes que a necessidade apareça;

- Promotor de qualidade: incentiva e motiva sua equipe a trabalhar de forma a atingir os padrões estabelecidos;

- Responsável: cumpre as obrigações, assume as conseqüências por seus atos e de seus subordinados;

- Descentralizador: atribui tarefas certas a seus subordinados, delegando autoridade e cobrando responsabilidade;

- Seguro: é auto-confiante; decidido e firme em suas decisões;

- Tolerante: admite os limites individuais e falhas pois acredita que isto faz parte do processo de aprendizado;

- Visionário: é capaz de enxergar as circunstâncias favoráveis para a empresa nos cenários atual e futuro.

Além dessas variáveis acrescentam-se aspectos relativos à informática globalizada, pois na atualidade é inadmissível a um engenheiro não dominar a informática. A falta de conhecimento de informática, que é mais comum aos engenheiros que se formaram há mais de vinte anos e que não lidam com a internet, pode ser um fator negativo na sua sobrevivência profissional.

O conhecimento de línguas universais é outra ferramenta poderosíssima, não apenas pela necessidade de comunicação, como também para desenvolvimento de projetos arrojados, visto que a maioria dos artigos e livros técnicos que são publicados estão em línguas estrangeiras. 
Revista Eletrônica de Ciência Administrativa (RECADM) - ISSN 1677-7387

Faculdade Cenecista de Campo Largo - Coordenação do Curso de Administração v. 4, n. 1, maio/2005 - http://revistas.facecla.com.br/index.php/recadm/

\subsection{Estrutura Curricular}

Segundo Rompelman (2001), o programa do curso de Engenharia deve ser elaborado de forma a conferir aos diplomados o seguinte conjunto de aptidões e habilidades:

- Aplicar o conhecimento da Matemática;

- Projetar e realizar experiências, bem como para analisar e interpretar dados;

- Projetar um sistema, um componente ou um processo, de modo a satisfazer determinadas necessidades;

- Atuar em equipes multidisciplinares;

- Identificar, formular e resolver problemas de engenharia;

- Ser responsável nos níveis profissional e ético;

- Comunicar-se de maneira efetiva;

- Cultura geral suficientemente ampla para perceber o impacto das soluções da engenharia no contexto comunitário global;

- reconhecimento da necessidade de um aprendizado contínuo e vitalício, e capacidade para engajar-se nesse aprendizado;

- conhecimento dos assuntos ligados à realidade contemporânea;

- Usar as técnicas, as habilidades e as modernas ferramentas da engenharia necessárias ao exercício profissional.

Esses devem ser considerados como o conjunto das especificações a que os diplomados devem obedecer. Apesar da abrangência destas especificações, o currículo deve oferecer condições de preparação do engenheiro de modo a garantir acesso para diversas carreiras e para uma vida profissional de atualização contínua. O currículo também deve ser capaz de atrair indivíduos talentosos e com os mais diferentes perfis para o desafio intelectual que representa o trabalho em engenharia, tanto na área tecnológica quanto de sistemas e suporte (UFSC, 2001).

No entanto Costa e Silva (2001), afirma que devem ser acrescentadas ainda competências de caráter ambiental, pois são grandes as preocupações a respeito do impacto ambiental provocado pelo desenvolvimento tecnológico, cujas implicações podem afetar a sobrevivência da raça humana. 
Revista Eletrônica de Ciência Administrativa (RECADM) - ISSN 1677-7387

Faculdade Cenecista de Campo Largo - Coordenação do Curso de Administração v. 4, n. 1, maio/2005 - http://revistas.facecla.com.br/index.php/recadm/

O ensino da manutenção precisa ser mais difundido, pois em muitas universidades esta disciplina inclui-se apenas como uma daquelas obrigatórias do curso. Portanto, deve ser repensada a necessidade de dar-se mais atenção a esta disciplina, visto que no processo produtivo o engenheiro precisa dominá-la com muita freqüência. No apêndice desta pesquisa encontra-se um exemplo do que está sendo oferecido como formação do Engenheiro de Sistemas.

Está na hora de jogar no lixo as antigas idéias de como fazer e ensinar manutenção, pois a tendência atual é que a manutenção esteja voltada à busca da eliminação das causas das falhas e dos desgastes das máquinas e do pessoal envolvido. A manutenção corretiva do "quebra-conserta" deverá sumir dos procedimentos normais. A manutenção preventiva e preditiva está evoluindo para manutenção pró-ativa.

Sabe-se ainda que as empresas utilizam somas significativas para manter os equipamentos disponíveis para a produção. Em muitas indústrias este custo varia em torno de $5 \%$ a $20 \%$ do faturamento da empresa (Intermega, 2001). Além dos custos diretos, os custos indiretos devido à perda de produção, ao retrabalho, ao refugo extrapolam os custos diretos de manutenção. Os ganhos na área de manutenção industrial impactam diretamente nos lucros da empresa. Estas argumentações justificam as atenções que devem ser dadas ao ensino da manutenção, portanto indispensáveis para que o engenheiro possa qualificar-se constantemente e sobreviver no mercado.

Quanto à segurança no trabalho, as universidades precisam dar mais ênfase a esta questão. É preciso rever o atual sistema de segurança e saúde do trabalhador, adequando-o à dinâmica das transformações tecnológicas e das relações de trabalho, avaliando o conteúdo das disciplinas e estabelecendo seus princípios e diretrizes de acordo com as necessidades atuais.

De acordo com o Ministério do Trabalho (2001), em 1997, 2819 pessoas morreram por acidentes de trabalho e outras milhares ficaram mutiladas e tiveram de ser aposentadas por invalidez. Esses fatos mostram que o engenheiro precisa conhecer a realidade das condições de trabalho do povo brasileiro.

A aquisição de tal conhecimento confere-lhe maior diferencial na corrida pelo emprego, além de ser uma maneira de contribuir para a promoção de maior 
Revista Eletrônica de Ciência Administrativa (RECADM) - ISSN 1677-7387

Faculdade Cenecista de Campo Largo - Coordenação do Curso de Administração v. 4, n. 1, maio/2005 - http://revistas.facecla.com.br/index.php/recadm/

estabilidade do processo de produção da empresa em que ele venha trabalhar e garantir a integridade física das pessoas, pois contribuir para que um acidente não ocorra é um dever de qualquer engenheiro.

Em síntese, para sobreviver profissionalmente, no mercado globalizado, o engenheiro precisa não apenas de conhecimento técnico, mas precisa também ser capaz de trabalhar em equipes multidisciplinares e executar tarefas de diferentes áreas. Além disso, ele precisa estar em sintonia com este mercado e acompanhar, constantemente, o processo das inovações tecnológicas. Portanto, os desafios do engenheiro neste terceiro milênio extrapolam as habilidades comuns que se exigiam num passado bem recente. Devem ser acrescentados outros conhecimentos como administração de pessoal, mercado financeiro, políticas internas e externas, domínio da informática e da informação, aspectos de impacto ambiental, além de amplo domínio de línguas universais, manutenção e segurança no trabalho. Não se deve ainda desprezar a necessidade da educação continuada como forma de qualificação constante.

A universidade também precisa estar em sintonia com as necessidades do mercado. Por isso, ela precisa buscar sempre a inovação de seus currículos para atender à demanda do sistema produtivo, pois a velocidade com que as mudanças estão ocorrendo, está exigindo maior flexibilização de suas atividades instrucionais. $\mathrm{Na}$ economia globalizada e diante da velocidade do desenvolvimento tecnológico, é necessária uma avaliação criteriosa dos objetivos da universidade na formação do engenheiro.

Tal reformulação deve torná-lo capaz de aplicar os conhecimentos científicos e tecnológicos no processo de produção, de forma que ele possa sobreviver profissionalmente e ter condições de qualificar-se constantemente. Finalmente, cabe a cada engenheiro, individualmente, preparar-se com dedicação e qualidade para garantir sua qualificação profissional, baseando-se nas exigências desse mercado cada vez mais competitivo.

O mundo dos negócios transformou o mercado de trabalho, alterando as estruturas organizacionais, remodelando o perfil de mão de obra e passando a exigir replanejamentos contínuos de metas em busca de resultados sempre positivos. Como uma verdadeira guerra, sem limites e sem derrotas aceitáveis, 
Revista Eletrônica de Ciência Administrativa (RECADM) - ISSN 1677-7387

Faculdade Cenecista de Campo Largo - Coordenação do Curso de Administração v. 4, n. 1, maio/2005 - http://revistas.facecla.com.br/index.php/recadm/

essas empresas buscam manterem-se em vantagem competitiva por uma questão de sobrevivência. Esta posição de alerta máximo a toda hora retifica a afirmativa de Tzu: "O mundo dos negócios não é diferente do campo de batalha [...] Não é diferente da Guerra, onde um mau planejamento pode levar à perda de pessoas, equipamentos e da própria batalha." (Sum Tzu, 1999).

\subsection{A Importância do tomador de Decisão no Ambiente Corporativo}

A liderança é hoje mais importante do que nunca. Em organizações tradicionais, as pessoas simplesmente cumpriam ordens. Agora, no entanto, as pessoas precisam estar inspiradas e a tarefa de suprir essa inspiração cabe à liderança. Isso exige um conjunto distinto de habilidades e um novo tipo de estilo. O líder antigo era um tomador de decisões e um despachante de ordens. O novo líder é um arquiteto organizacional e um visionário

Diversos teóricos - entre eles Michael Polanyi v, citado por Barroso \& Gomes (1999, p.3) e Serafim Filho (1999, p.2) - definem conhecimento com dois significados: por um lado, seria um corpo de informações representando fatos, opiniões, idéias, teorias, princípios e modelos, ou seja, o conhecimento expresso como informação; por outro, pode referir-se ao estado do indivíduo em relação àquele conjunto de informações, o qual pode ser ignorância, consciência, familiaridade, entendimento, habilidade etc.

Afirmam os autores também que o conhecimento pode ser de dois tipos: o tácito ou informal, que é sutil, pessoal, envolve crenças, perspectivas e valores, e refere-se à experiência e à habilidade dos indivíduos para realizar as tarefas; e o explícito ou formal, que pode ser articulado através da linguagem e transmitido como informação e é ligado aos procedimentos, bancos de dados, patentes, documentos e aos relacionamentos com clientes e parceiros.

Como afirmam Keating, Robinson \& Clemson (1999, p.6), as organizações já sabem as respostas para muitos de seus problemas, mas como esse conhecimento é freqüentemente tácito, permanece adormecido e relativamente pouco utilizado. Mas ele pode ser transformado em explícito através de um processo de reflexão e diálogo e, a partir daí, articulado, explanado ou 
Revista Eletrônica de Ciência Administrativa (RECADM) - ISSN 1677-7387

Faculdade Cenecista de Campo Largo - Coordenação do Curso de Administração v. 4, n. 1, maio/2005 - http://revistas.facecla.com.br/index.php/recadm/

representado e, em seguida, compartilhado e utilizado nas decisões e resoluções de problemas. Esses autores também alertam (1999, p.8) para o fato de que embora a valorização do conhecimento tácito seja freqüentemente vista como verdadeira chave para resolver problemas e criar novos valores - sendo o explícito considerado apenas como suporte - isso pode, precisamente por ser inconsistente e não pode ser examinado, ocultar a necessidade ou possibilidade de alternativas.

Porém, no caso em estudo, o desafio é ainda maior: o aluno de certo modo "sabe" mais que o professor! Não se trata, portanto apenas de motivação ou do processo em si de absorção de conhecimentos, mas de criar situações de aprendizagem efetivamente mútua, onde as temáticas sejam dadas pela vivência, pela percepção e pela necessidade dos estudantes.

O tácito torna-se paradigma e não pode ser contestado. O tácito é também difícil de articular - sabemos mais do que podemos falar. Finalmente, sua transmissão é mais lenta e tem alto custo, além de requerer que as comunicações aconteçam face-a-face para que os erros de interpretação, decorrentes da ambigüidade natural, possam ser profundamente corrigidas através de feedback pessoal.

\section{Metodologia}

\subsection{Tipo de Pesquisa}

$\mathrm{Na}$ pesquisa de campo deste estudo, realizada no segundo semestre de 2003, adotou-se o enfoque exploratório (Vergara, 1977) e qualitativo, dando o máximo de extensão e profundidade à coleta de dados. A amostra, contendo 80 empresas do Grande Rio de Janeiro, foi por julgamento randômica.

$\mathrm{Na}$ análise dos dados, foi considerada também uma subcategoria do setor de serviços, as "empresas de conhecimento", ainda não examinada em estatísticas e pesquisas no Brasil. Stewart 1998, (apud Valente, 1998, p.27) conceitua as "empresas de conhecimento" como sendo "aquelas que possuem capital intelectual e cujo valor é significativamente maior do que o valor de seus 
Revista Eletrônica de Ciência Administrativa (RECADM) - ISSN 1677-7387

Faculdade Cenecista de Campo Largo - Coordenação do Curso de Administração v. 4, n. 1, maio/2005 - http://revistas.facecla.com.br/index.php/recadm/

ativos porque o mercado está disposto a pagar a diferença em função do conhecimento de que dispõem e que representa grande expectativa de lucro futuro". Nesta subcategoria, entraram empresas cujo "produto" depende essencialmente do conhecimento, ou é o próprio conhecimento das pessoas envolvidas no trabalho: consultoras, escolas, empresas de software, empresas de treinamento, etc.

\subsection{Amostra}

Foram consideradas empresas com até 100 funcionários, o que englobaria, segundo algumas classificações, em particular o SEBRAE (1999), as categorias micro, pequenas e médias empresas. No entanto, em outras classificações, este critério define apenas as de pequeno porte. Na verdade, para uma pesquisa qualitativa sobre conhecimento e capacidade de lidar com a complexidade, como é o caso desta, o que realmente importa é o fato de que a gestão e o controle do negócio são exercidos diretamente pelos proprietários.

Finalmente, as empresas deviam ter mais de 5 anos de existência, critério utilizado por vários estudiosos do tema - entre eles Filion (1999, p.20) — para caracterizar "empresas de sucesso" e que, no caso brasileiro, mostra-se ainda mais adequado devido às crônicas dificuldades econômicas e sociais do país. Devido ao caráter qualitativo do estudo, focado no conhecimento específico de cada tipo de negócio, e à possível multiplicidade de atividades de cada empresa, as 80 empresas da amostra, na verdade, foram vistas suficientes para os objetivos da pesquisa.

\subsection{Pesquisa Aplicada}

A pesquisa foi aplicada a profissionais que trabalham no ramo de informática em diversos seguimentos do mercado. Tais profissionais deveriam estar regularmente empregados e desempenhar atividades voltadas a gestão de informação em qualquer setor da empresa. As empresas deveriam ser do Estado do Rio de Janeiro e possuir uma estrutura que fizesse uso dos recursos de informática. O emprego de Engenheiros de informação com formação completa 
Revista Eletrônica de Ciência Administrativa (RECADM) - ISSN 1677-7387

Faculdade Cenecista de Campo Largo - Coordenação do Curso de Administração v. 4, n. 1, maio/2005 - http://revistas.facecla.com.br/index.php/recadm/

não foi exigido, possibilitando uma visão abrangente do uso da informática nestas organizações. A própria condição de ser pequena ou média, já apresenta motivos para que a empresa não mantenha em seus quadros funcionais um profissional de elevado custo, o que contribuiu muito para as conclusões obtidas.

Foram escolhidos 80 profissionais de informática porque estes profissionais fazem parte do foco do estudo e possuem conhecimento sobre a estrutura interna da organização em que operam, além de obterem dados sobre a operacionalização da empresa, seu segmento de mercado e modelos existentes no mercado em que atuam.

As perguntas elaboradas e descritas no Anexo $A$, foram planejadas de forma a captar dos entrevistados sua visão de gestão, sua importância da estrutura em que se encontram e sua participação no processo decisório da empresa em que atuam. Foram abordados ainda aspectos como o Faturamento Anual Médio e o Ramo de Atividade da empresa, possibilitando uma visão distribuída quanto aos segmentos abordados pela pesquisa. Também foi abordado pela pesquisa as oportunidades de aperfeiçoamento de seus funcionários ligados a tecnologia, pedra fundamental para que haja vantagem competitiva em a ser utilizada pela administração na tomada de decisão.

A identificação de uma estrutura ligada à área de processamento de dados através do número de profissionais foi abordada para que os elementos recolhidos possibilitassem o discernimento entre as oportunidades de ascensão ou não dentro da organização. Esta estrutura é facilmente encontrada em grandes empresas, mas o fato de serem identificadas na pesquisa nos permite apontar para uma estratégia de gestão arrojada para o tipo de empresa em questão.

\section{RESULTADOS E DISCUSSÃO}

De acordo com a pesquisa realizada, foram obtidos dados que nos levam a afirmação de que tanto os profissionais da área de tecnologia quanto a administrativa das empresas estudadas concordam com o fato de serem necessárias informações sobre a dinamização do processo decisório, com base nos aspectos organizacionais internos e a penetração no mercado globalizado. Foram ressaltados vários aspectos relevantes e elucidativos sobre a percepção 
Revista Eletrônica de Ciência Administrativa (RECADM) - ISSN 1677-7387

Faculdade Cenecista de Campo Largo - Coordenação do Curso de Administração v. 4, n. 1, maio/2005 - http://revistas.facecla.com.br/index.php/recadm/

do conhecimento real e da utilização da informação na esfera decisória da empresa.

O trabalho mostrou que as empresas entrevistadas foram adotando a tecnologia sem saber o real benefício que ela poderia trazer. Assim, os administradores implantaram a Informática com o objetivo de automatizar seus processos sem que houvesse planos de expansão ou adequação a realidade de alta volatilidade de componentes e custos associados. Apesar de parte dos entrevistados ocuparem cargos de desenvolvimento e atuarem na produção de tecnologia aplicada ao funcionamento do negócio, não foram detectados valores agregados ao produto final que pudesse ser "adquirido" pelo consumidor.

No planejamento da adoção da tecnologia, não houve análise de resultados de impactos ou ganhos, visto que a visão empregada partiu de uma postura comercial imediata, com vistas à obtenção de dividendos a curto e médio prazos. Com a visão de tecnologia puramente aplicada aos processos organizacionais, não se pode ir além da detecção de picos de atendimentos e processos. Torna-se necessária a visão crítica de quem irá absorver a mudança de processos no tratamento de dados e principalmente da percepção do cliente final.

Torna-se necessário nesse momento uma reflexão sobre as decisões que hoje o mercado tem tomado como sendo "necessária" a sobrevivência através da informatização de seu parque funcional. Este realidade só se concretiza, e isto a pesquisa mostra claramente, com a adoção de medidas conjuntas entre a visão empreendedora dos administradores e criadores de soluções integradas. Como isto será possível? Através de uma ação conjunta entre o empresário e o engenheiro de sistemas, de modo a criar soluções que utilizem o potencial da tecnologia atual com vistas à contínua adequação dos processos de manutenção da obtenção de dados renovados, captados junto aos consumidores e colaboradores. As atividades diárias de um pequeno empresário passam por várias atividades que não o permitem atualizar-se com alta taxa de atualizações tecnológicas lançadas ao mercado rotineiramente.

É preciso que alguém que tenha sólida formação no ambiente técnico e experiência em atualização e acomodação a esta alta freqüência de mudanças, 
Revista Eletrônica de Ciência Administrativa (RECADM) - ISSN 1677-7387

Faculdade Cenecista de Campo Largo - Coordenação do Curso de Administração v. 4, n. 1, maio/2005 - http://revistas.facecla.com.br/index.php/recadm/

possa adequar todo este aparato à realidade da empresa e leva-la, segundo as diretrizes traçadas por ambos - empresário e engenheiro - à frente de suas concorrentes em sua atividade fim.

O planejamento pode ser feito de forma explorativa, de forma reativa ou ainda de forma antecipativa (estratégica).

$\mathrm{Na}$ forma explorativa, a ênfase é dada a repetição de fenômenos do passado, onde são resgatados os dados que ocorreram antes e que deverão ocorrer novamente, para previsão do futuro. Na forma reativa, a ênfase é dada aos fatos que estão ocorrendo no presente, sem preocupação com o futuro. Porém, o planejamento antecipativo ou simplesmente estratégico é que permite a organização se preparar adequadamente para o futuro, evitando surpresas em suas transformações ou mudanças, na busca constante da qualidade $\mathrm{e}$ competitividade.

Embora o planejamento estratégico seja conceitualmente da alta administração da organização, é comum nos dias de hoje, a participação de outros níveis hierárquicos no desenvolvimento dessa atividade. Ora, a adoção do modelo proposto aqui não está longe de uma realidade já experimentada para uma grande parcela do empresariado brasileiro, embora não haja registro oficial da participação destes segmentos na construção da linha de ação da empresa.

Pensar por antecipação, pensar naquilo que ainda vai acontecer, com base nos fatos do cotidiano e na alta volatividade do mercado tecnológico na atualidade forma o espírito do engenheiro de sistemas e o prepara para o planejamento, conferindo a este profissional o potencial necessário para se alcançar o sucesso.

\section{CONCLUSÃO}

O trabalho demonstrou a influência da reestruturação produtiva, resultante do desenvolvimento e capacidades e da participação do engenheiro de sistemas na administração direta das Pequenas e Médias empresas. No perfil do engenheiro, ora considerado como gestor, devido à concentração de funções próprias ao administrador tradicional, revela uma concentração maior de atribuições ligadas as habilidades de inter-relacionamentos humanos e motivação 


\section{Revista Eletrônica de Ciência Administrativa (RECADM) - ISSN 1677-7387 \\ Faculdade Cenecista de Campo Largo - Coordenação do Curso de Administração v. 4, n. 1, maio/2005 - http://revistas.facecla.com.br/index.php/recadm/}

para o desempenho, aliados à psicologia social, à liderança e ainda à questões econômicas estratégicas da organização.

As novas relações de trabalho, promovidas pelo estreitamento do relacionamento com a administração efetiva da empresa, conduziram o engenheiro a atuar em gestão, a partir de sua entrada no mercado de trabalho de forma empreendedora e independente, tornando-o colaborador igualitário aos empreendedores do negócio.

Como o profissional de Sistema de Informação possui em sua formação elementos que apontam para uma complementaridade de necessidades e requisitos existentes no âmbito da tomada de decisão, o empresário tem, em si mesmo, o controle eficaz sobre a tecnologia a ser utilizada e se sente altamente capaz.

Esta pesquisa procurou ressaltar que, após uma análise abrangente das contribuições que um engenheiro de sistemas pode oferecer e as implicações no processo de tomada de decisão por parte dos gestores, podem resultar em um alinhamento quanto a métodos e técnicas científicas propostas pelos engenheiros focados nas realidades do mercado. Outra contribuição teórica importante desta pesquisa diz respeito a identificação da promoção deste alinhamento estratégico em nível operacional por meio dos sistemas informatizados. Observa-se que em uma das entrevistas elaboradas pela pesquisa, a participação dos profissionais do sistema de informação, quando presentes, são sempre requisitados para prestar esclarecimento ou fornecer dados que sozinhos os empresários não são capazes de interpretar e adequar às necessidades da empresa.

No processo em que tanto empresários quanto engenheiros estão envolvidos e que ambos terão que concordar para que haja algo palpável com que se possa trabalhar, o fator que certamente influirá decididamente será a congruência de fatos e relatos partilhados por ambos em um processo simbiótico. Dados financeiros terão que ser liberados para o conhecimento do engenheiro e dados operacionais de projetos terão que ser preparados para que possa servir de endosso aos atos da diretoria.

Para tanto, torna-se necessária a utilização de procedimentos e técnicas que possibilitem aos pequenos empresários desenvolver a capacidade de transformar 
Revista Eletrônica de Ciência Administrativa (RECADM) - ISSN 1677-7387

Faculdade Cenecista de Campo Largo - Coordenação do Curso de Administração v. 4, n. 1, maio/2005 - http://revistas.facecla.com.br/index.php/recadm/

o conhecimento tácito em explícito através da integração do saber e do fazer. Neste contexto, os procedimentos a serem desempenhados pelos Engenheiros de Sistemas são os seguintes:

- Informar-se das prioridades e metas a curto prazo (conhecimento dos assuntos ligados à realidade contemporânea);

- Planejar formas de penetração no mercado futuro pretendido (proativo);

- Formular alternativas de procedimentos na atuação direta com os clientes através da tecnologia (inovador);

Com todo o knowhow técnico do engenheiro de sistemas, de modo que um processo exploratório de idéias seja estimulado, ele acabará promovendo a transformação da situação que gera o bloqueio e rejeição em relação à aprendizagem conjunta em uma situação de crescimento conjunto e amigável (motivador).

Com estes resultados e o modelo de alinhamento proposto, algumas contribuições são significativas para a área de planejamento estratégico das organizações, tais como:

- A confirmação da importância da promoção do alinhamento entre o Engenheiro de Sistemas e o empresariado;

- A inclusão de variáveis de estudos realizados na área de Sistemas de Informação;

- Metodologia na implementação e;

- A incorporação das etapas do processo de planejamento estratégico como um todo.

O foco do modelo passa a ser a promoção do modelo contínuo para todo o horizonte de planejamento, evidenciando a persistência do processo no ciclo de vida da organização. A visão passa a ser de gerenciamento das estratégias do negócio, tendo a tecnologia como um recurso obrigatório para o sucesso do negócio.

Como resultado maior desta pesquisa, tem-se que o grande desafio da área, refere-se à operacionalização do alinhamento sugerido. Como sugestão de adequação a essa realidade temos a inclusão no currículo do Engenheiro de 
Revista Eletrônica de Ciência Administrativa (RECADM) - ISSN 1677-7387

Faculdade Cenecista de Campo Largo - Coordenação do Curso de Administração v. 4, n. 1, maio/2005 - http://revistas.facecla.com.br/index.php/recadm/

Sistemas a Disciplina de Prática de Negociação, em que o engenheiro de sistemas teria variáveis a serem manipuladas de acordo com uma realidade de mercado extraída da vivência de pequenas empresas da região. Um trabalho de campo em que a realidade e a teoria seriam utilizados na forja das novas competências profissionais de forma dinâmica.

No decorrer das pesquisas e entrevistas que garantiram a autenticidade dos dados relatados, foram feitos questionamentos sobre "qual a melhor forma de operacionalizar a integração entre os fatores aqui abordados".

Os resultados obtidos permitiram crer que a operacionalização do alinhamento deve se efetivar por meio da modelagem de um conjunto informal, contendo os controles operacionais e gerenciais do negócio consolidados em indicadores criados e adotados por ambos - Engenheiros e Empresários - que reflitam os objetivos e as estratégias organizacionais e suas metas. Esta instrumentação da gestão, aliada a uma política de incentivos para os recursos humanos e garantindo a participação dos engenheiros envolvidos, deve favorecer a promoção do alinhamento em maior intensidade.

Quando digo que a política de participação é uma alternativa viável, isso não significa a criação de uma sociedade, o que poderia se supor no caso de uma pequena empresa. Digo que com a adoção do modelo de gestão participativa dinâmica entre empresário e engenheiro, o negócio poderá ser alavancado através de cotas sobre o resultado positivo alcançado.

Este fato já é bastante conhecido nas grandes empresas, quando engenheiros de sistemas - então chamados de CIOs (Chief Information Office) operam como parceiros da empresa, desvinculando-se quando o projeto de adequação ao mercado globalizado termina.

O fato de os empresários das pequenas e médias empresas não estarem abertos a partilhar dos dividendos conquistados podem emperrar o crescimento e comprometer a sintonia necessária ao modelo funcional, mas a participação sobre os resultados positivos e a valorização do esforço mútuo, contribuirá para o crescimento organizacional e, com isto, o beneficiamento e a recompensa pela implantação do novo modelo de gestão. 
Revista Eletrônica de Ciência Administrativa (RECADM) - ISSN 1677-7387

Faculdade Cenecista de Campo Largo - Coordenação do Curso de Administração v. 4, n. 1, maio/2005 - http://revistas.facecla.com.br/index.php/recadm/

\section{REFERÊNCIAS}

Barroso, Antônio Carlos O. \& Gomes, Elisabeth B. P. Tentando Entender a Gestão do Conhecimento. Revista de Administração Pública. Vol. 33, n. ${ }^{0}$, mar/abr 1999, p. 147-170.

Bateman, T. S. \& Snell, S. A. Administração: Construindo Vantagem Competitiva. São Paulo: Atlas, 1998.

Bruno-Faria, Maria de Fátima \& Brandão, Hugo Pena - ANPAD - Revista de Administração Contemporânea, Jan./Abr. Artigo de 1997.

Campos, Vicente Falconi. TQC: Controle da Qualidade Total (no estilo Japonês). Rio de Janeiro: Bloch, 1992.

Carvalho, Luiz Carlos S. Análise de sistemas: o outro lado da informática. Rio de Janeiro, Editora LTC, 1988, p.110.

Reflexões empíricas sobre a abordagem sistêmica na organização: buscando a prática apesar da perplexidade. Anais do XVI ENANPAD, Salvador, 1993.

Clementi, Sérgio. Metodologia para Especificação e Implementação de Soluções de Gerenciamento em Redes de Computadores Corporativas. 1999. Dissertação (Mestrado) - Escola Politécnica da Universidade de São Paulo, São Paulo, SP.

Costa e Silva, A. C.. Uma Grande Indústria Silenciosa. Revista Brasileira de Saneamento e Meio Ambiente - Bio. Associação Brasileira de Engenharia Sanitária e Ambiental- ABES, Rio de Janeiro, 2001, p.5

Exame, Revista O Paradoxo do Emprego, Editora Abril, 2000, pp. 182-183.

Filion, Louis J. Empreendedorismo: Empreendedores e Proprietários-Gerentes de Pequenos Negócios. Trad.: Maria Letícia Galizzi e Paulo Luz Moreira. Revista de Administração. São Paulo, v. 34, n 2, p. 05-28, abril/junho 1999.

Hoffman, E. A Auto-Realização no Local de Trabalho no Século 21, disponível em:www.economiabr.net .

Intermega. Planejamento da Manutenção Industrial. Disponível em: www.intermega.com.br. Acesso em Junho de 2000.

Jornal Estado de Minas. Classificados-Pequenos Anúncios, Junho de 2001

Keating, Charles \& Robinson, Thomas \& Clemson, Barry. A Method for Organizational Learning. Norfolk, Virginia, Old Dominion University, 1999, p. 1-12. 
Revista Eletrônica de Ciência Administrativa (RECADM) - ISSN 1677-7387

Faculdade Cenecista de Campo Largo - Coordenação do Curso de Administração v. 4, n. 1, maio/2005 - http://revistas.facecla.com.br/index.php/recadm/

Mattar, F. N. , Perfil do Líder Para o Ano 2000. Disponível em: www.economiabr.net. Acesso em abril de 2002

Ministério do Trabalho. Estatística dis Acidentes de Trabalho em 1997. Disponível em: www.economiabr.net. Acesso em julho de 2001.

Nascimento, N. O, Elementos Para uma Reflexão Sobre a Inovação do Ensino de Engenharia, Anais do XXI Congresso Brasileiro de Ensino de Engenharia (COBENGE 1993), Belo Horizonte-MG, Vol. 1, pp. 168

Oliveira, Marco Antonio G. O Novo Mercado de Trabalho: Guia para iniciantes e Sobreviventes. Rio de Janeiro: SENAC 2000

Orssatto, Carlos H. ; Orssatto, Mara T.C. ; Gasparetto, Valdirene ; Kopittke, Bruno H. Ensino de Custos com Auxílio dos Jogos de Empresa. Disponível em: www.ufsc.br. UFSC - Universidade Federal de Santa Catarina., 1999, p. 1-6.

Polito, R. Como Apresentar Projetos ou Produtos Com Sucesso, Disponível em : www.economiabr.net. Acesso em julho de 2001.

Rocha, Luiz Augusto de Giordano. Jogos de Empresa: Desenvolvimento de um Modelo para Aplicação no Ensino de Custos Industriais. Disponível em: www.ufsc.br. UFSC, 1997, p. 1-6.

Rompelman, O. Avaliação do Aprendizado: A Evolução dos Objetivos no Ensino de Engenharia e Suas Conseqüências no Tocante a Avaliação. Tradução de Paulo dos Santos Ferreira, Universidade de Tecnologia de Delft, Holanda, 2001.

SEBRAE - Serviço Brasileiro de Apoio às Micro e Pequenas Empresas Definição de micro, pequena e média empresa. Disponível em: www.sebraerj.gov.br. Acesso em fevereiro, 2000

- Pesquisa Fatores Condicionantes e Taxa de Mortalidade de Empresas. Disponível em: www.sebraerj.gov.br. Acesso em outubro, 1999.

Serafim Filho, Pedro. A Gestão do Conhecimento e a Motivação nas Organizações. Disponível em: www.economiabr.net. Acesso em Janeiro 1999, p. 1-9.

Singer, P. O Brasil na Crise, Perigos e Oportunidades, São Paulo: Contexto, 1999 Stewart, Thomas. Capital Intelectual. A nova vantagem competitiva das empresas. Rio de Janeiro: Campus, 1998. 
Revista Eletrônica de Ciência Administrativa (RECADM) - ISSN 1677-7387 Faculdade Cenecista de Campo Largo - Coordenação do Curso de Administração v. 4, n. 1, maio/2005 - http://revistas.facecla.com.br/index.php/recadm/

Sum Tzu et al. A arte da guerra e do gerenciamento. Rio de Janeiro - Record, 1999.

Tina, C. TELEMANAGEMENT FORUM, 1998; ISO/IEC JTC1/SC2/WG7, 1993 e 1994.

UFSC - Universidade Federal de Santa Catarina. Perfil do Engenheiro Eletricista. Curso de Graduação em Engenharia Elétrica. Disponível em: www.ufsc.br. Acesso em março de 2001

Valente, Marcelo S. Caracterização de Empresas de Alta Tecnologia: Uma Extensão do Modelo Stuart, 1999. Dissertação (Mestrado em Administração) — COPPEAD/UFRJ, Rio de Janeiro, RJ.

Vergara, S. V. Projetos e relatórios de pesquisa em Administração. São Paulo, Atlas, 1997. 